\title{
Effect of aluminum oxide sandblasting, plasma application and their combination on the bond strength of resin cement to zirconia ceramics
}

Efeito do jateamento de óxido de alumínio, aplicação de plasma e sua combinação na resistência de união do cimento resinoso à zircônia

Beatriz Curvello de MENDONÇA ${ }^{1}$, William Matthew NEGREIROS ${ }^{1}$, Marcelo GIANNINI ${ }^{1}$

1- Department of Restorative Dentistry - Piracicaba Dental School - University of Campinas - Piracicaba - SP - Brazil.

\section{ABSTRACT}

Objective: to evaluate the effect of aluminum oxide sandblasting (AOS), argon plasma application (APL) and their combination (AOS+APL) on the shear bond strength (SBS) of dual-cure resin cement (Panavia F 2.0, Kuraray Noritake) to two zirconia-based ceramics (Lava, 3M ESPE and Katana, Kuraray Noritake). Material and Methods: One hundred twenty zirconia plates $(13 \mathrm{~mm}$ in length X $5 \mathrm{~mm}$ in width $\mathrm{X} 1 \mathrm{~mm}$ in thickness) were prepared and treated according to the following treatments: 1- AOS, 2- APL,3- AOS+APL and 4no treatment (control). After treatments, resin cement cylinders $(1.4 \mathrm{~mm}$ in diameter $\mathrm{x} 1 \mathrm{~mm}$ in height) bonded to zirconia surface were obtained by filling up the silicon matrix. The shear bond test was performed following storage of the samples for 24 hours and one year. Bond strength values were recorded in $\mathrm{MPa}$ and the data were analyzed by three-way ANOVA and Tukey post-hoc test (preset alpha of 0.05). Results: In general, AOS and AOS +APL showed the higher SBS. After one-year storage, SBS of the resin cement to the Katana zirconia did not reduce, regardless of the zirconia surface treatment. Conclusion: AOS alone was able to increase the SBS of the resin cement to both zirconia ceramics compared to control and SBS remained stable after one year depending on type of zirconia ceramic.

\section{KEYWORDS}

Aluminum Oxide; Ceramics; Plasma; Resin Cements.

\section{RESUMO}

Objetivo: avaliar o efeito do jateamento de óxido de alumínio (AOS), aplicação de plasma de argônio (APL) e sua combinação (AOS + APL) na resistência ao cisalhamento (SBS) do cimento resinoso dual (Panavia F 2.0, Kuraray Noritake) a duas cerâmicas à base de zircônia (Lava, 3M ESPE e Katana, Kuraray Noritake). Material e Métodos: Cento e vinte placas de zircônia (13 mm de comprimento X $5 \mathrm{~mm}$ de largura X $1 \mathrm{~mm}$ de espessura) foram preparadas e tratadas de acordo com os seguintes tratamentos: 1- AOS, 2- APL, 3- AOS + APL e 4 - sem tratamento (controle). Após realizados os tratamentos, com a utilização de uma matriz de silicone $(1,4 \mathrm{~mm}$ de diâmetro $\mathrm{x} 1 \mathrm{~mm}$ de altura) foram confeccionados cílindros de cimento resinoso na superfície da zircônia. O teste de cisalhamento foi realizado após o armazenamento das amostras por 24 horas e um ano. Os valores de resistência de união foram registrados em $\mathrm{MPa}$ e os dados foram analisados por ANOVA de três fatores e teste post-hoc de Tukey (alfa de 0,05). Resultados: Em geral, AOS e AOS + APL apresentaram a maior SBS. Após um ano de armazenamento, o SBS do cimento resinoso para a zircônia Katana não reduziu, independentemente do tratamento da superfície da zircônia. Conclusão: AOS isoladamente foi capaz de aumentar a SBS do cimento resinoso para ambas as zircônias em comparação com o controle e a SBS permaneceu estável após um ano, dependendo do tipo de zircônia.

o

\section{PALAVRAS-CHAVE}

Cerâmica; Gases em plasma; Resistência ao cisalhamento. 


\section{INTRODUCTION}

Y

ttria-stabilized

polycrystals

tetragonal

zirconia (Y-TZP) have gained prominence in the field of Dentistry because of their favorable mechanical and aesthetic properties that enable this material to be used appropriately as an alternative for indirect restorations with metallic infrastructure. However, its molecular structure and composition does not allow good adhesion to the resin cements without treatment of their surfaces [1]. Some studies have suggested combining micromechanical retention and chemical bonding in order to provide efficient adhesion of resin cements to zirconia ceramics. For the traditional ceramics, the hydrofluoric acid etching that aims to dissolve the glassy phase and create microporosities does not promote the same results for Y-TZP, because zirconia ceramics contain only crystalline phase without the glassy phase [2].

Studies have shown that the sandblasting with aluminum oxide abrasive particles creates roughness on the Y-TZP ceramic [3] and when compared to other types of treatments, such as laser irradiation [4] better bonding is obtained. Although these methods yield satisfactory results, the mechanical stress caused by the sandblasting with abrasive particles produces surface defects following the repetitive impacts of the aluminum oxide particles [5]. Thus, the damage generated may be detrimental in the long-term and the fatigue resistance of zirconia-based ceramics may decrease after sandblasting [6], as demonstrated by Zhang et al. [7], in which sandblasting reduce zirconia flexural strength by up to $30 \%$ compared to well-polished specimens.

A possible alternative would be the use of plasma generated from argon gas. Plasma acts by changing the functional groups on different treated surfaces to render an inactive (nonpolar) material reactive (polar), without its structural properties being impaired [8]. The application of plasma increases the surface energy of the treated substrate, favoring molecular chemical interactions and consequently has the ability to promote better adhesion results between Y-TZP and resin cements $[9,10]$. In order to test the ability of argon plasma to improve the bond strength, this study evaluated the effect of sandblasting with aluminum oxide, argon plasma application and their combination on the shear bond strength of resin cement to two Y-TZP ceramics. Additionally, to estimate the bonding durability of resin cement to treated zirconia; samples were testedafter waterstorage for 24 hours and one year. The null hypotheses were that (1) argon plasma alone or combined with sandblasting would not improve the bond strength when compared to untreated zirconia and (2) the water-storage for one year would not reduce the bond strength.

\section{MATERIAL AND METHOD}

Materials and Experimental groups

Sixteen experimental groups were formed according to two Y-TZP ceramics investigated (Katana, Kuraray Noritake Dental Inc., Tokyo, Japan and Lava, 3M ESPE, St. Paul, MN, USA), two storage times of the specimens in water (24 hours and 1 year) and four surface treatments of the zirconia, which were:

- None (control)

- Argon plasma application( 30 seconds) seconds)

- Aluminum oxide sandblasting (20

- Aluminum oxide sandblasting + argon plasma application

\section{Sample preparations}

Sixty Katana plates and 60 Lava plates with dimensions $13 \mathrm{~mm}$ long X $5 \mathrm{~mm}$ wide X 1 $\mathrm{mm}$ thick were used. The plates were obtained from CAD/CAM disks, which were cut with a diamond disk (Buehler) and flattened with 600-grit SiC abrasive paper before sintering. The zirconia plates were randomly divided into 16 groups $(\mathrm{n}=15)$. 
Sandblasting was performed for 20 seconds, using and $50 \mu \mathrm{m}$ aluminum oxide abrasive particles and microetcher intraoral sandblaster (Danville Materials, Inc., San Ramon, CA, USA). Argon plasma treatment used was the Surface plasma tool model SAP - Lab applications (Surface - Engineering and Plasma Solution Ltda, Campinas, SP, Brazil). Argon was used as the working gas (Praxair 4.8, White Martins Gases Ind. S.A., Rio de Janeiro, RJ, Brazil), with an output of 1.0 liter per minute.

After surface treatments or not (control), two cylindrical silicon matrices were positioned on the zirconia surfaces. The dualcure resin cement (Panavia F 2.0, Kuraray Noritake Dental Inc., Tokyo) was manipulated according to the recommendations of its manufacturer and applied into the hole of the matrices using an explorer probe \# 5 (Hu-Friedy Mfg.Co. LLC, Chicago, IL, USA). Afterwards, the resin cement was photoactivated for 20 seconds with a light-curing unit $\left(860 \mathrm{~mW} / \mathrm{cm}^{2}\right.$, Valo, Ultradent Products Inc., South Jordan, UT, USA). The matrices were removed and two resin cement cylinders with dimensions of 1.4 $\mathrm{mm}$ in diameter and $1 \mathrm{~mm}$ in height (bonding area of $1.53 \mathrm{~mm} 2$ on the zirconia surface). The zirconia plates with the two resin cement cylinders were stored in deionized water at 370C for 24 hours.

\section{Shear bond strength test}

The zirconia plates were fixed to shear device using cyanoacrylate-based glue (Super Bonder, Loctite/Henkel Ltda, Diadema, SP, Brazil), which was coupled to the universal test machine (EZ-Test, Shimadzu, Kyoto, Japan). The loading was applied to the base of the resin cement cylinders with a bladeshaped device at a speed of $0.5 \mathrm{~mm} / \mathrm{min}$ until fracture. One cylinder of the resin cement was tested after 24 hours and the other after one year of storage in water. This water was replaced every 15 days. The value of each specimen was obtained in kilogram-force $(\mathrm{KgF})$ and was converted into MegaPascal (MPa). Shear bond strength data were analyzed by three-way (factors under study: Treatment, Type of zirconia and Evaluation time)analysis of variance (ANOVA; repeated measures approach) and Tukey post-hoc test (preset alpha of 0.05).

\section{RESULTS}

Means and standard deviations of shear bond strength obtained are presented in Table 1.Three-way ANOVA showed that bond strength results were influenced significantly by the treatmentused $(p<0.0001)$, type of zirconia $(p<0.0001)$ and storage period $(p<0.0001)$. Also, the double interactions "treatment vs type of zirconia" and "type of zirconia vs storage period" were significant ( $p$ $=0.0009$ and $p<0.0001$, respectively).

For Lava zirconia at 24 hours, Tukey's post-hoc test revealed that sandblasting resulted in higher bond strength than control and plasma application. The combination between plasma and sandblasting did not differ from the control, sandblasting and plasma application alones. All these bond strengths significantly reduced after one year and the comparison among group kept the same.

For Katana zirconia at 24 hours, control and plasma application showed lower bond strengths than those obtained for sandblasting and its combination with plasma. After one year, no reduction in bond strength of resin cement to Katana was observed and the differences among groups also kept the same at one year. 
Table 1 - Mean (SD) of bond strength versus material, treatment and time (in MPa)

\begin{tabular}{|c|c|c|c|}
\hline \multirow{2}{*}{ Material } & \multirow{2}{*}{ Treatment } & \multicolumn{2}{|c|}{ Time } \\
\hline & & 24 hours & 1year \\
\hline \multirow{4}{*}{ Lava } & None (control) & $13.2(3.6) \mathrm{Ab}$ & $5.4(1.8) \mathrm{Bb}$ \\
\hline & Plasma & $12.3(3.8) \mathrm{Ab}$ & $7.4(4.0) \mathrm{Bb}$ \\
\hline & Sandblasting & $19.4(3.9) \mathrm{Aa}$ & *9.1(7.3) Ba \\
\hline & $\begin{array}{c}\text { Sandblasting + } \\
\text { Plasma }\end{array}$ & 16.8 (6.6) Aab & ${ }^{\star} 7.5$ (2.3) Bab \\
\hline \multirow{4}{*}{ Katana } & None (control) & $9.8(4.0) \mathrm{Ab}$ & $9.3(3.5) A b$ \\
\hline & Plasma & $10.3(4.7) \mathrm{Ab}$ & $7.4(4.0) \mathrm{Ab}$ \\
\hline & Sandblasting & $19.6(2.3) \mathrm{Aa}$ & $19.5(7.3) \mathrm{Aa}$ \\
\hline & $\begin{array}{c}\text { Sandblasting + } \\
\text { Plasma }\end{array}$ & 19.5 (5.1) $\mathrm{Aa}$ & 17.7 (6.2) Aa \\
\hline
\end{tabular}

Means followed by different letters (capital letters compare time within the same treatment and lower case letters compare treatments within the same time) differ among them ( $p \leq 0.05)$. * Differ from Katana for the same treatment and time $(p \leq 0.05)$.

\section{DISCUSSION}

The null hypothesis stating that the treatments with argon plasma application or combined with aluminum oxide sandblasting would not improve the bond strength of the resin cement to zirconia was rejected, because the bond strength obtained by the combination of sandblasting and plasmawas higher than that ofcontrol for Katana zirconia, although the treatment with plasma only did not differ from untreated zirconia ceramics. The second hypothesis was also rejected, because the bond strength of the resin cement to Lava zirconia decreased after one year.

Studies that evaluate the bond strength of adhesive materials to zirconia have suggested that their stable monoclinic phase has little adhesiveness. It known that when the zirconia surface is treated withaluminum oxide abrasive particles, a surface roughnesswith microretentions is created, which increases the superficial area for bonding of resin cement to zirconia[11].Also, if different zirconia surface pre-treatments are compared, it can be noted that higher bond strength occurred when zirconia was treated with aluminum oxide sandblasting compared to other types of treatment, such as laser irradiation, silica coating or etchings[4].

In this study, the combination of sandblasting and argon plasma application provided adequate bond strength results, but did not differ statistically from treatment with only sandblasting. Thus, to simplify the zirconia treatment before bondingonly sandblasting would be necessary. Although the sandblasting method has satisfactory results for bonding zirconia, the mechanical stress caused by the aluminum oxide sandblastingcan produces surface defectsdue to the repetitive impacts of the abrasive particles [5]. Therefore, the damages generated by sandblasting can be harmful in the long term, compromising the fatigue resistance and flexural strength of zirconia ceramics $[7,12]$.

An alternative to the sandblasting would be the use of non-thermal plasma generated from argon gas. Plasma acts by changing the functional groups on different treated surfaces, so that a material in a state of chemical (apolar) equilibrium can become reactive (polar), without its structural properties being impaired [13]. The application of the plasma has the objective of increasing the surface energy of the treated substrate, favoring the molecular chemical interactions and, consequently, the ability to promote better bond strength results between zirconia and resin cement $[14,15]$. It has been seen in the literature that the plasma application can be performed from various techniques and a study showed an increase in the adhesive capacity of zirconia-treated surface compared to aluminum oxide sandblasting, when it was subjected to an argon gas plasma treatment for 20 minutes [1].The plasma application time in this study was $30 \mathrm{~s}$, maybe it was too short to increase the bond strength of resin cement to zirconia ceramics compared to longer times of plasma application. The composition of the gas can also vary andinfluence the results, asthe combination of argon gas with oxygen in plasma application have been shown to be very effective in increasing the bond strength of resin cements to zirconia, when compared to treatment with pure argon gas [6]. 
In this study it was used a10-MDP (10-methacryloyloxyydecyl dihydrogen phosphate)-based resin cement, which has presented the best bond strength results to zirconia[16,17,18,19].10-MDPis an adhesion promoter monomer able to bond to the ceramics oxides that is the main characteristic Y-TZP zirconias. There are different chemical states of the 10-MDP bonds with zirconia by ionic and hydrogen bonding between them. Also, specific concentration of 10-MDP seems important to improve the bond strength to zirconia [18]. However, in this study, the bond strength 10-MDP-based resin cement to Lava zirconia decreased after one year, even using this adhesive cementing system, with sandblasting and/or plasma applications.This decrease in bond strength may be more relevant in the cases of using resin cements without 10-MDP monomer[20].A previous application of 10-MDP-based primers or plasmamight be beneficial for increasing the bond strength of resin cement to zirconia [14,15, 21, 22, 23].

Two types of Y-TZP ceramics weretested in this study: Lava (3M Qral Care) and Katana (Kuraray Noritake Dental). The few compositional differences between Lava and Katana zirconia ceramics reflected in the few differences in the bond strength results between them. Lava contains $99 \%$ zirconium oxide and $1 \%$ other components, while Katana presents94.4\% zirconium oxide,5.4\% yttrium and $0.2 \%$ other components. At 24 hours, no statistical difference between the zircônia ceramics was observed. However, after storage for one year, the bond strength of resin cement to zirconia reduced for the groups, in which Lava zirconiawassandblasted or combined with plasma. Unlike the Lava, the bond strength to Katana that was sandblasted or sandblasted + plasma kept stable after one year, remaining with bond strength values close to $20 \mathrm{MPa}$. Because Katana zirconia and Panavia F 2.0 resin cement were developed by the same company, the interaction between the zirconia and resin cement seemed effective and more lasting. The aging method used in this study only considered the hydrolytic degradation, since no loading and other types of external chemical challenges were applied to the samples. Also, the zirconia bond strength results of this study were specific for the resin cement used, since MDP-based resin cements produce greater bond strength to zirconia than other types of luting materials. The type of zirconia might produce variable results, although little difference between Lava e Katana zirconia was observed in this study. Regarding plasma technology, the use of plasma generator equipment is simple and for clinical use in dentistry, it has a handpiece that facilitates the plasma application. The need for a source of argon gas, cost and maintenance may limit its wide use.

\section{CONCLUSION}

Higher Y-TZP zirconia ceramic bond strengths of resin cement were found when zirconia was sandblasted or combined with argon plasma.Bond strength results following one-year water storage did not change for Katana zirconia.

\section{ACKNOWLEDGMENTS}

This study was supported by grants from SAE/UNICAMP and CNPq (307217-2014-0), Brazil.

\section{REFERENCES}

1. Kaimal A, Ramdev P, Shruti CS. evaluation of effect of zirconia surface treatment, using plasma of argon and silane, on the shear bond strength of two composite.J Clin Diagn Res.2017 Aug;11(8):ZC39-ZC43

2. Flamant Q, Marroa FG, Rovira JJR, Anglada M. Hydrofluoric acid etching of dental zirconia. Part 1 : etching mechanism and surface characterization. J Eur Ceram Soc. 2016 Jan;36(1):121-34.

3. Ramos-Tonello CM, Trevizo BF, Rodrigues RF, et al. Pre-sintered Y-TZP sandblasting: effect on surface roughness, phase transformation, and Y-TZP/veneer bond strength. J Appl Oral Sci. 2017 NovDec;25(6):666-73.

4. Inokoshi M1, De Munck J, Minakuchi S, Van Meerbeek B. Meta-analysis of bonding effectiveness to zirconia ceramics. J Dent Res. 2014 Apr;93(4):329-34.

5. Mosele JC, Borba M. Effect of particle sandblasting on the bond strength and mechanical behavior of zirconia-based ceramics review.Cerâmica. 2014 Apr-Jun;60(354):179-86 
6. Tabari K, Hosseinpour S, Mohammed Rahimi H. The impact of plasma treatment of $\operatorname{cercon} \circledast$ zirconia ceramics on adhesion to resin composite cements and surface properties. J Lasers Med Sci. 2017 Summer;8(Suppl 1):S56-S61.

7. Zhang Y, Lawn BR,Rekow ED, Thompson VP. Effect of sandblasting on the long-term performance of dental ceramics. J Biomed Mater Res B Appl Biomater. 2004 Nov;71(2):381-6.

8. Liao Y, Liu XQ, Chen L, Zhou JF, Tan JG. Effects of different surface treatments on the zirconia-resin cement bond strength. Beijing DaXueXue Bao Yi Xue Ban.2018 Feb 18;50(1):53-7.

9. Valverde GB, Coelho PG, Janal MN, Lorenzoni FC, Carvalho RM, Thompson VP, Weltemann KD, Silva NR. Surface characterization and bonding of Y-TZP following non-thermal plasma treatment. J Dent. 2013 Jan;41(1):51-9. doi:10.1016/j.jdent.2012.10.002. Epub 2012 Oct

10. Lopes. BB, Ayres. APA, Lopes. LB, Negreiros. WM, Giannini. M. The effect of atmospheric plasma treatment of dental zirconia ceramics on the contact angle of water. Appl Adhes Sci. 2014May;2:17. Doi: $10.1186 / 2196-4351-2-17$

11. Sarmento HR, Campos F, Sousa RS, Machado JPB, Souza ROA, Bottino MA, Özcan M (2014) Influence of air-particle deposition protocols on the surface topography and adhesion of resin cement to zirconia, Acta Odontol Scand. 2014 Jul; 72(5):346-53. doi: 10.3109/00016357.2013.837958. Epub 2013 0ct 31.

12. Zhang Y, Lawn BR, Malament KA, Van Thompson P, Rekow ED.Damage accumulation and fatigue life of particle-abraded ceramics. Int $J$ Prosthodont.2006 Sep-0ct;19(5):442-8.

13. Duan YX, Huang C, Yu QS. Cold plasma brush generated at atmospheric pressure. Review ScientInstrum 2007 Jan;78(1):015104

14. Park C, Yoo SH, Park SW, Yun KD, Ji MK, Shin JH, Lim HP.The effect of plasma on shear bond strength between resin cement and colored zirconia.J AdvProsthodont. 2017 Apr;9(2):118-23
15. Pott PC, Syväri TS, Stiesch M, EisenburgerM.Influence of nonthermal argon plasma on the shear bond strength between zirconia and different adhesives and luting composites after artificial aging. $J$ AdvProsthodont. 2018 Aug;10(4):308-14.

16. Thammajaruk P, Inokoshi M, Chong S, Guazzato M. Bonding of composite cements to zirconia: A systematic review and metaanalysis of in vitro studies.J MechBehavBiomed Mater. 2018 Apr;80:258-68.

17. Llerena-Icochea AE, Costa RM, Borges A, Bombonatti J, Furuse AY. Bonding Polycrystalline Zirconia With 10-MDP-containing Adhesives. Oper Dent. 2017 May-Jun;42(3):335-41.

18. Nagaoka N, Yoshihara K, Feitosa VP, Tamada Y, Irie M, Yoshida Y, Van Meerbeek B, Hayakawa S.Chemical interaction mechanism of 10-MDP with zirconia. Sci Rep. 2017 Mar 30;7:45563.

19. Özcan M, Bernasconi M. Adhesion to zirconia used for dental restorations: a systematic review and meta-analysis.J AdhesDent. 2015 Feb;17(1):7-26.

20. de Sá Barbosa WF1, Aguiar TR, Francescantonio MD, Cavalcanti AN, de Oliveira MT, Giannini M.Effect of water storage on bond strength of self-adhesive resin cements to zirconium oxide ceramic.J AdhesDent. $2013 \mathrm{Apr} ; 15(2): 145-50$.

21. Zhao L, Jian YT, Wang XD, Zhao K.Bond strength of primer/cement systems to zirconia subjected to artificial aging.J ProsthetDent. 2016 Nov;116(5):790-796. doi: 10.1016/j.prosdent.2016.03.020. Epub 2016 Jun 14

22. Ahn JS, Yi YA, Lee Y, Seo DG.Shear Bond Strength of MDP-Containing Self-Adhesive Resin Cement and Y-TZP Ceramics: effect of Phosphate Monomer-Containing Primers.Biomed Res Int. 2015;2015:389234.

23. Yagawa S, Komine F, Fushiki R, Kubochi K, Kimura F, Matsumura H.Effect of priming agents on shear bond strengths of resin-based luting agents to a translucent zirconia material.J Prosthodont Res. 2018 Apr;62(2):204-9.

Beatriz Curvello de Mendonça

(Corresponding address)

Rua Waldyr Aparecido da Silva, 30

Campinas, SP, Brazil

Zip Code: $13085-065$

Date submitted: 2018 Jan 24

E-mail: bia.mendo@yahoo.com.br 